\title{
ECOlogy of DeER on Devils Tower National Monument
}

\author{
Greg W. McDaniel $\downarrow$ Evelyn Merrill $\downarrow$ Fred Lindzey \\ DePartment of ZoOlogy AND Physiology \\ Wyoming CoOperative Fish and Wildlife Research Unit \\ UNIVERSITY OF WYOMING \\ LARAMIE
}

\section{$\downarrow \quad$ INTRODUCTION}

Currently, white-tailed (Odocoileus virginianus) and mule deer ( $O$. hemionus) use Devils Tower National Monument and adjacent private agricultural lands year round or migrate from the Monument to other areas. Construction of a game proof fence by adjoining landowners threatens to enclose Devils Tower National Monument. If this occurs, deer use of the Monument may be substantially altered and longterm management of the population may be faced with many of the problems associated with island reserves. National Park Service management policy charges the Monument to detect or predict changes in the natural resources under its stewardship. However, current deer use of the Monument is not well documented so that a baseline for monitoring long term changes is lacking.

The University of Wyoming Department of Zoology and Physiology and the Wyoming Cooperative Fish and Wildlife Research Unit, in cooperation with the University of Wyoming National Park Service Research Center and Devils Tower National Monument, initiated a study in June 1990 to document the population and habitat ecology of whitetailed and mule deer on Devils Tower National
Monument. Objectives of the study during this reporting period were to:

1. radio-collar a representative sample of the adult female population of deer

2. radio-locate adult does to identify daily and seasonal habitat use and movement patterns

3. determine seasonal deer densities on the Monument

\section{$\downarrow \quad$ Methods}

During June and July, deer were darted using a Simons dart-gun and Palmer 2.5-ml barbless darts. Dosages of succinylcholine chloride (Sucostrin) ranged between 5.0 to $5.2 \mathrm{mg} /$ per animal. Deer were eartagged with Wyoming Game and Fish eartags. Adult does were instrumented with activity sensitive radio-collars. Deer were aged by examining tooth eruption and wear patterns. Body measurements were recorded.

Every week to 10 days, radio-collared does were relocated during 4 time periods (3:01 to 9:00, 9:01 to $15: 00,15: 01$ to $21: 00$ and 21:01 to 3:00) during a 2day sequence. The sequence of relocating each radio- 
collared doe was randomized within a time period. Relocations were classified as visual location, triangulation within $300 \mathrm{~m}$, triangulation within $1 \mathrm{~km}$, or triangulation greater than $1 \mathrm{~km}$. Efforts were made to obtain visual sightings. Sex and age classification of deer within an estimated $100 \mathrm{~m}$ of radio-collared does were also recorded when observations were made.

Deer relocations were marked on aerial photos or 1:24000 scale topographic maps. Vegetation type within an estimated $45 \mathrm{~m}$ radius of radio-collared does was recorded.

Starting in August, deer surveys were conducted on a monthly basis. Straight-line transects were randomly placed either north and south or east and west across the Monument. Transect lines were walked during morning or late afternoons. Our data suggest that deer regularly use the Monument at this time. Each time a group of deer was observed, the sight distance and compass bearing from observer to the middle of the group of deer was measured with a range-finder and compass. Habitat in which the deer was located was recorded. These data will be used to assess estimates of populations numbers using a strip census approach.

Forty-two pellet group density plots were established on the Monument in October to determine seasonal deer use. Plots were placed along a systematic grid with the grid located from a random starting point. Plots are circular with a radius of $5.2 \mathrm{~m}$ and an area of 0.01 hectares. Plots were cleared of all deer pellets so that only new deposits of pellet groups will be counted in the spring.

A complete survey of deer on the Monument was attempted with a drive count of deer on October 20. Stationary observers were placed along the east and south borders of the Monument, while 25 people walked in a straight line from the northern border to the southern border. Species and number of deer crossing back through the line to the north and deer crossing between the stationary observers were recorded. Observers were not located along the west border of the Monument because it was fenced.

\section{$\downarrow \quad$ Results}

Between June 18 and July 21, 1990, 12 whitetailed and 4 mule deer adult does were captured and radio-collared. One yearling buck was captured but only eartagged.

By mid-summer, radio-collared white-tailed deer irregularly moved off the Monument to nearby irrigated hay meadows in the evenings and returned to the Monument in early morning. By the end of August, 6 of 12 marked white-tailed deer and 1 of 4 marked mule deer were using the hay meadows. By the end of October, all deer except 1 mule deer had been located off the Monument. Movement of marked does on and off the Monument occurred primarily along the eastern and southern borders of the Monument. The game fence along the western and northern border of the Monument inhibited movement across these areas. One site along the fence showed definite signs of deer movement under it. Shortly after this observation, this portion of the fence was modified.

During September and October, concurrent with deer hunting adjacent to the Monument, 1 radiocollared deer was killed by hunters and another deer was injured. We have not been able to obtain signals from 2 other does since September. It is unknown whether these does have migrated away from the Monument or whether they were killed by hunters. Movement off the monument continued through September and October despite the opening of hunting season. No obvious change was evident in use of major movement corridors during this time.

Estimates of population numbers from our line transect surveys are too preliminary to report at this time. One hundred and seventeen white-tailed and 63 mule deer were counted during the deer drive conducted on October 20 . We view these numbers as minimum counts because animals were missed. Yet, the drive count has potential to provide fairly accurate estimates of deer numbers. However, we estimate that more people will be needed, to be confident that all deer are counted.

\section{FUTURE WORK}

We will continue to monitor deer movements, habitat use, and population trends during late fall and winter 1990-91. In December we will establish vegetation transects to monitor seasonal forage use during the upcoming 2 years. Pellet group plots will be sampled again in April of 1991 and additional plots established based on these results. 